\title{
La violencia en las escuelas desde la perspectiva de sus actores. El caso de una escuela secundaria de la Ciudad de México
}

Chuquilin Cubas, Jerson; Zagaceta Sarmiento, Maribel

La violencia en las escuelas desde la perspectiva de sus actores. El caso de una escuela secundaria de la Ciudad de México

Revista Educación, vol. 41, núm. 2, 2017

Universidad de Costa Rica, Costa Rica

Disponible en: http://www.redalyc. org/articulo. $0 a ? i d=44051357009$

DOI: http://dx.doi.org/10.15517/revedu.v41i2.21751

Esta obra está bajo una Licencia Creative Commons Atribución-NoComercial-SinDerivar 3.0 Internacional. 


\section{La violencia en las escuelas desde la perspectiva de sus actores. El caso de una escuela secundaria de la Ciudad de México}

Violence in schools from the perspective of its actors. The case of a high school in Mexico City

Jerson Chuquilin Cubas [1]

Universidad Pedagógica Nacional, México

DOI: http://dx.doi.org/10.15517/revedu.v41i2.21751

jchuquil@uc.cl

Maribel Zagaceta Sarmiento [2]

Colegio Hispano Americano Superior, México

mzagacet@uc.cl

Recepción: 09 Noviembre 2015

Aprobación: 23 Marzo 2017

\section{Resumen:}

Este artículo tiene como propósito analizar algunas formas de violencia que se desarrollan en una escuela secundaria pública del Distrito Federal, México, de un modo tal que afloren los factores que le subyacen. Para lograrlo, asumimos la perspectiva de investigación cualitativa como la más adecuada para estudiar los hechos sociales considerados violentos y las percepciones y apreciaciones que los sujetos construyen sobre esos hechos en situaciones de interacción inscritas en el contexto escolar. A partir de los registros de observación y los discursos del profesorado y el alumnado, sostenemos que en esta escuela se producen formas de conflictividad general caracterizadas por relaciones opuestas entre el profesorado y el alumnado, que terminan en violencias simbólicas, emocionales y gestuales. También formas de violencia física manifestadas en peleas cuerpo a cuerpo, juegos bruscos y casos aislados de violencia contra el profesorado. En algunos casos la escuela está directamente involucrada y en otros casos los problemas de violencia se imbrican con otros factores sociales y culturales que le dan poder y significado.

PaLABRas ClaVe: Violencia escolar, educación secundaria obligatoria, percepciones y apreciaciones, etnografía.

\section{Abstract:}

This article aims to analyze some forms of violence that take place in a public high school in the Federal District, in such a way to surface the factors underlying it. To achieve this, a qualitative Research methodology was used as the most appropriate mean to understand the link between violent considered social facts and perceptions and judgments that subjects build on these facts in situations of interaction enrolled in the school context. Based on the observation records and speeches of teachers and students in this school we argue that forms of general conflict characterized by conflicting relationships between students and teachers, ending with symbolic, emotional and gestural violence occur. Also forms of physical violence manifested in melee fighting, horseplay and isolated cases of violence against teachers. The findings suggested that in some cases, the school is directly involved and in other cases the problems of violence are interwoven with other social and cultural factors that give power and meaning.

\section{NOTAS DE AUTOR}

[1] Doctor en Pedagogía de la Universidad Nacional Autónoma de México, Magister en Administración Educacional de la Pontificia Universidad Católica de Chile. Ha recibido becas de estudios de posgrado del Programa Internacional de Becas de la Fundación FORD y del Gobierno de México a través de la Secretaria de Relaciones Exteriores. Ha publicado artículos de investigación y desarrollado conferencias sobre la formación y el trabajo docente. Ha desempeñado las funciones de docencia, gestión e investigación en el nivel de Licenciatura y Posgrado en dos universidades peruanas y en la Benemérita y Centenaria Escuela Normal de Guanajuato, México. Ha trabajado como profesor invitado en el Doctorado en Educación del Centro Universitario de Ixtlahuaca y, en la Maestría en Educación del Instituto Universitario Internacional de Toluca, México. Trabajó como profesor investigador titular "A" de tiempo completo en la Universidad Intercultural Maya de Quinta Roo, México. En esta institución coordinó el Programa de Maestría en Educación Intercultural y el Programa de Formación Básica Trabajó también como académico de tiempo completo en el Departamento de Educación de la Universidad Iberoamericana, Ciudad de México. Actualmente trabaja como profesor de tiempo completo, titular "A" en la Universidad Pedagógica Nacional-Unidad 291-Tlaxcala, México. Participa también, en el Proyecto colectivo de investigación "La educación secundaria: Problemática y retos al inicio del siglo" adscrito al Instituto de Investigaciones sobre la Universidad y la Educación (IISUE) de la Universidad Nacional Autónoma de México (UNAM), coordinado por la doctora Patricia Ducoing Watty.

[2] Es Doctora en Pedagogía de la Universidad Nacional Autónoma de México, Maestra en Desarrollo Humano de la Universidad Iberoamericana, Ciudad de México. Es Licenciada en Educación en la Especialidad de Educación Física y Licenciada en Psicología. Ha recibido becas de estudios de posgrado del Programa Internacional de Becas de la Fundación FORD y del Gobierno de México a través del Consejo Nacional de Ciencia y Tecnología (CONACYT). Ha realizado una estancia de investigación en la Universidad de Córdoba, España. Autora del libro Felipe el Grajiento y otros relatos de mi tierra y otras obras literarias inéditas. Ha desarrollado conferencias sobre desarrollo humano, violencia escolar, danza educativa y motivación estética en la literatura. Ha desempeñado las funciones de docencia en educación básica y en dos universidades peruanas. Ha trabajado también en la Maestría en Educación del Instituto Universitario Internacional de Toluca, México y en el Instituto de Logoterapia el Altillo de la Ciudad de México. Ha trabajado como psicopedagoga en escuelas de educación básica. Actualmente trabaja como académica en la Universidad Pedagógica Nacional - Unidad 291 - Tlaxcala - México. 
KEYWORDS: School violence, secondary education, perceptions and insights, ethnography.

\section{INTRODUCCIÓN}

Este artículo es parte de una investigación que tiene como objeto de estudio la violencia en una escuela secundaria de la Ciudad de México. La investigación tuvo como propósito develar las principales formas de violencia que se manifiestan en la escuela secundaria, los factores que le subyacen y cómo se involucra la escuela en el desarrollo de estos procesos. Esto implicó poner en el primer plano de la investigación a la población participante, ya que los comportamientos considerados violentos aparecen configurados por sus subjetividades y adquieren sentido en situaciones de interacción inscritas en el espacio escolar donde se desenvuelven.

El tema de la violencia en las escuelas ha cobrado gran relevancia, magnificado en parte por la cobertura mediática de los medios de comunicación. Este posicionamiento se ha proyectado de manera inusitada en la agenda científica y en la política educativa mexicana. También es tema de interés de instituciones supranacionales. Tal es el caso que la Organización de las Naciones Unidas ha implementado, a través de sus agencias especializadas, una serie de programas y proyectos relacionados con la violencia en las escuelas (Monclús Estella, 2005).

Como tema de interés científico, la violencia en las escuelas es una cuestión de interés reciente en la academia mexicana. Según Gómez y Zurita (2013), el posicionamiento de este tema en la agenda de investigación ha pasado por tres grandes momentos: a) momento inaugural (1996-2004); b) reconocimiento explícito del tema (2005-2008) y c) búsqueda de alternativas (2009 a la actualidad). Si bien, esta periodización es solo una aproximación al tema en referencia, muestra que la violencia en las escuelas se ha convertido en un objeto de reflexión teórica y de intervención explícita.

Las investigaciones sobre la violencia en las escuelas, por lo general, combinan aspectos de distintos modelos teóricos y metodológicos, y subrayan la multidimensionalidad del fenómeno de la violencia. Destacan la manifestación de formas y tipos de violencia disimiles, que, además, no siempre responden a las mismas causas. De hecho, en todas las escuelas no se producen los mismos episodios de violencia y no todas estas violencias son de la misma índole.

Este artículo tiene como propósito analizar algunas formas de violencia que se desarrollan en una escuela secundaria pública de la Ciudad de México, de un modo tal que afloren los factores que le subyacen. Para cumplir esta intención, el artículo se organiza en cuatro núcleos temáticos. El primero, alude al enfoque teórico que entreteje la perspectiva interpretativa y la teoría sustantiva sobre la violencia en las escuelas. El segundo núcleo temático se refiere a la perspectiva metodológica. Específicamente, se utiliza la etnográfica como el método más adecuado para la producción de la evidencia empírica. El tercer núcleo se refiere a las situaciones de violencia protagonizadas en la escuela. El análisis se hace a partir de los registros de observación, la revisión de los archivos existentes en el departamento de tutoría y los discursos de la población participante. En el cuarto núcleo temático presentamos, a modo de resultados, algunas ideas sobre las violencias sistémicas y relacionales. Finalmente, a modo de cierre, presentamos algunas conclusiones que abren otras aristas del tema.

\section{Perspectiva teórica}

Este apartado tiene como propósito explicitar el punto de vista desde donde abordamos el objeto de investigación. En este sentido, en los párrafos que siguen, explicamos brevemente la perspectiva epistemológica y teórica que fundamenta la investigación en la que se ancla este artículo. Posteriormente, aludiremos al método y a los procedimientos seguidos en la construcción de la evidencia empírica. 
Partimos del supuesto de que los comportamientos considerados violentos adquieren sentido en situaciones de interacción inscritas en el contexto social en el que se desarrollan. Estos se expresan de tal forma que es posible captarlos mediante aproximaciones comprensivas. En este sentido, consideramos que la perspectiva de investigación interpretativa (Taylor y Bodgan, 1992) es la más adecuada para abordarlos. Desde esta mirada, los actores educativos se ubican en el primer plano de la investigación. Y quienes investigan no solo observan y describen los episodios de violencia, sino también interactúan con los sujetos protagonistas de estas acciones para comprender las percepciones y apreciaciones que construyen al respecto.

Ahora bien, la violencia en las escuelas es un fenómeno complejo que eslabona los hechos considerados violentos y las representaciones que los sujetos construyen sobre tales hechos. Según Dubet (1988), la violencia designa a la vez conductas potenciales o realmente violentas y la percepción que los sujetos construyen sobre esos riesgos. Este fenómeno es abordado desde diversas disciplinas y posicionamientos teóricos. Quienes han hecho de este tema su objeto de investigación, tratan de explicarlo focalizando su atención en factores biológicos, psicológicos, socioculturales e institucionales (Míguez, 2012).

Dentro de este panorama de significaciones, se glosan los aportes de Míguez (2012) por considerar que ayudan a explicar las formas de violencia que se describen más adelante. El autor, basado en los aportes teóricos de Elías, que enfatiza las relaciones entre los individuos, destaca la controversia que existe en la representación de la violencia en las escuelas y advierte de sus implicancias en los procesos de investigación. A estos aspectos se aluden en los párrafos siguientes.

En el campo de las ciencias sociales, las representaciones que se construyen sobre la violencia son objeto de controversias. Uno de los principales ejes en la discusión es la confrontación entre los razonamientos que postulan una definición restringida de la violencia y aquellos que plantean una definición amplia de esta misma. En el primer caso, la tendencia es acotar la definición al uso de la fuerza para infligir daño físico grave hacia otros. La perspectiva amplia, en cambio, considera que la violencia física es solo una de las múltiples formas que la violencia puede asumir. Que existen otras formas sutiles, como la violencia simbólica y emocional, $\mathrm{u}$ otras manifestaciones que son vividas traumáticamente por las victimas. Esta controversia evidencia, por lo menos, tres aspectos que tenemos en cuenta en nuestra investigación.

En primer lugar, la violencia es una construcción socialmente determinada. Esto supone que la violencia como objeto de conocimiento existe dentro de determinados paradigmas de pensamiento que la nombran como tal. Así, quienes proponen una definición restringida de violencia, consideran que es posible progresar en el conocimiento de la realidad exterior a la conciencia a través del desarrollo de representaciones más precisas de la experiencia de los sujetos en el mundo. Esto es, un concepto absoluto de violencia o una representación de esta que exprese, sin ninguna ambigüedad ni parcialidad, la experiencia que la realidad produce. En cambio quienes postulan definiciones amplias, parten del supuesto de que la experiencia que tenemos del mundo no es independiente de las representaciones que nos hacemos de ella. En este sentido, las palabras son los instrumentos sensibilizadores para la interpretación de la realidad, sin que esto signifique correspondencia univoca con la realidad. Entonces, no se trata de llegar a un conocimiento total de la violencia en las escuelas, sino de multiplicar los puntos de vista mostrando la pluralidad del fenómeno y de perspectivas que pueden desarrollarse sobre él.

De lo anterior se sigue que la multiplicidad de sentidos atribuidos a la violencia aporta riqueza y profundidad al análisis. Empero, es necesario aproximarnos a una construcción conceptual de violencia, definiendo algunos rasgos que permitan la construcción del objeto que designa sin reducir la complejidad del fenómeno.

En segundo lugar, la oposición que plantea la controversia antes señalada advierte sobre dos riesgos presentes en la investigación sobre la violencia. Primero, el afán de buscar relaciones constantes y universales entre la realidad y las representaciones conceptuales que construimos de ella comporta el peligro de reificación. Esto es, confundimos el modelo que construimos de la realidad con la realidad misma, al suponer que las abstracciones que hacemos de ella lo encarnan, obviando que solo son representaciones 
de una porción de esa realidad y que la representan en función de la perspectiva particular desde la que realizamos esa abstracción. Segundo, al postular la imposibilidad de contrastar las representaciones intuitivas y circunstanciales que construimos sobre el mundo, con la experiencia recurrente, colectiva y de largo plazo que ese mundo genera en nosotros, definimos una relación estática entre la representación de la realidad y la realidad misma. Es decir, negamos la posibilidad de representar la experiencia de la realidad por fuera de las representaciones que construimos sobre ella.

En tercer lugar, los riesgos señalados anteriormente nos advierten sobre la parcialidad de las representaciones que construimos sobre la realidad. Para superarlo, Míguez (2012) postula una convergencia equilibrada en los métodos utilizados en el proceso de investigación. Esto permitiría una mayor comprensión de las múltiples formas de violencia en las escuelas. Empero, esto no significa que cualquier método vale, sino el más adecuado para traducir las preguntas de investigación en procedimientos para la producción de la evidencia empírica. Es decir, el método elegido, considerando cierto grado de libertad, debe ser coherente con los principios de la metodología en la que se encuadra (Sautu, 2005).

De lo anterior se colige que la violencia en las escuelas es una construcción social que a la vez construye el objeto que designa. Esta línea de argumentación sugiere que la violencia, como entramado conceptual, se construye a partir de la observación directa de las manifestaciones de la violencia y de ejercicios deductivos para establecer distinciones analíticas (Míguez, 2009). En este sentido, es posible nombrar múltiples formas de violencia y atribuirles orígenes distintos. Al respecto, Míguez (2012) identifica en una serie de investigaciones tres formas básicas de atribución de causalidad sobre la violencia en las escuelas. La primera alude a los rasgos de carácter individual asociados a la violencia. La segunda atribuye a las condiciones institucionales la emergencia de situaciones violentas. Específicamente alude a las pautas institucionales de convivencia, a las formas habituales de interacción y al contexto emocional que estas pautas generan en la aparición de episodios de violencia. La tercerea se refiere a los factores socioeconómicos (pobreza, marginalidad, segregación, etc.) que inciden en la producción de violencias.

A partir de tales distinciones analíticas, el autor concluye que estos tres campos de atribución causal no se comportan de la misma manera. Sugieren la existencia de formas específicas de asociación entre algunos tipos de violencia y las condiciones en que esta emerge. Y aportan evidencias en el sentido de que la multidimensionalidad no solo supone múltiples formas de violencia y múltiples factores que la producen, sino que también estos factores inciden de maneras diversas en la producción de violencias.

En este mismo orden de ideas, Míguez (2007) postula que la violencia en las escuelas está asociada:

... a factores vinculados a los niveles de integración de los alumnos a su comunidad educativa, a las condiciones de socialización provistas por su entorno familiar y a la estructura actitudinal del alumno. Así, variables como el rendimiento educativo, el agrado con el medio escolar, el clima social familiar, la capacidad de proyectar un futuro personal o, inversamente, pensar en acabar con la propia vida, son factores que se asocian a la condición de víctima o victimario de hechos violentos; mientras que el nivel económico del alumno no parece poseer capacidad explicativa. (p. 26)

Habría que decir también que la violencia, según Míguez (2007), no se reduce a la producción de daño físico. Sino que implica siempre la imposición arbitraria de una fuerza que es exterior a la víctima que la padece. Sin embargo, el supuesto de que la violencia solo es tal cuando el daño producido es vivido como imposición arbitraria por el sujeto que la padece pulveriza la distinción entre violencia legítima e ilegítima. Por eso, el entramado conceptual de la violencia incluye también formas de imposición naturalizadas que dejan de vivirse como imposiciones porque permiten la participación de los sujetos en el orden social.

Es más, Míguez (2007) sostiene que la violencia es un fenómeno cuya diversidad de formas se manifiesta en muchas dimensiones y parámetros. A esto se suman las diferencias en la percepción de la violencia. No todos los grupos y actores sociales perciben y definen lo que es o no es violento del mismo modo. En el campo educativo, el autor distingue formas de violencia sistémica y formas de violencia relacional. Las primeras están asociadas a la función escolar y responden a los mecanismos de dominación instituidos, es decir, se relacionan con el trabajo de configuración de las subjetividades del estudiantado, para que pueda adaptarse 
a la sociedad en que vive. La violencia relacional es horizontal y ocurre en la interacción entre los actores educativos, principalmente entre estudiantes.

\section{Perspectiva metodológica}

Como señalamos en la sección precedente, las situaciones sociales consideradas violentas son construidas por sus actores en un entramado complejo de relaciones. Para acceder a ellas es necesario explorar no solo las percepciones y apreciaciones que los actores educativos construyen al respecto, sino también conocer el contexto específico en el que interactúan. Por tal motivo utilizamos el método etnográfico de investigación. Al respecto, Goetz y LeCompte (1988) destacan la importancia de la etnografía educativa como la perspectiva más adecuada para la descripción, interpretación y explicación de los fenómenos educativos. Así, pues, asumimos la etnografía como un modo de producir evidencia empírica sobre el fenómeno de la violencia en las escuelas, pues se trata de un objeto que nos implica y que requiere ser observado y descrito con profusión.

La etnografía implica observar y registrar metódicamente hechos, seleccionar informantes y dialogar con estas personas, transcribir a textos las conversaciones e interpretar la información obtenida. Implica desarrollar descripciones densas y analizar la complejidad del entramado de relaciones que los constituyen, de tal manera que sea posible comprender las estructuras de significación subyacentes (Geertz, 2003). Para ello es necesario estar en el escenario de la investigación. Y esta forma de acercarse al estudio de los hechos sociales, en este caso el fenómeno de la violencia, disiente de la neutralidad axiológica.

La etnografía educativa como una forma de reconstrucción cultural de la vida humana en los espacios educativos demanda la utilización de procedimientos que permitan construir datos fenomenológicos de primera mano. Esto requiere interactuar con las personas durante mucho tiempo en el espacio donde transcurre su vida cotidiana. En el caso de esta investigación, uno de los investigadores estuvo en la escuela secundaria tres días por semana, desde agosto del 2012 hasta julio del 2014. Durante los primeros meses de trabajo en este espacio, se enfatizó la observación de la vida cotidiana del alumnado. Y luego, gradualmente, se empezaron a utilizar técnicas participativas como los grupos focales y a desarrollar entrevistas con el profesorado, personal tutor y estudiantes que se han involucrado en episodios de violencia. De este modo, el proceso de construcción del objeto de investigación se nutrió de información de primera fuente.

Conforme progresaba el trabajo, el proceso de observación se fue focalizando en los aspectos considerados más relevantes. Para ello fue necesaria la elaboración de una guía de observación y la información proporcionada por el personal de tutoría. Con la ayuda del personal de tutoría se organizó un cronograma de observación de clases. Considerando que el personal de tutoría son las personas más cercanas a las situaciones problemáticas, se inició observando el desarrollo de sus clases. Posteriormente se incluyó la observación de otras clases como las de matemática, historia y español. Esta decisión fue tomada a partir del diálogo con el alumnado reportado por haber participado en incidentes violentos.

Las entrevistas entendidas como los reiterados encuentros dialógicos entre quienes investigan y quienes acceden a participar en ellas, siguiendo a Taylor y Bogdan (1992), tuvieron el propósito de construir información sobre los hechos de violencia tal como las expresan con sus propias palabras las personas entrevistadas. Tanto el número y el tipo de informantes varió durante el proceso de trabajo de campo. $\mathrm{Al}$ igual que las observaciones, las entrevistas se iniciaron a partir de una idea general sobre las personas a entrevistar. Después de las entrevistas iniciales y la reflexión sobre estas, el curso de estas fue adquiriendo mayor profundidad en los aspectos que consideramos claves.

Las entrevistas con el personal docente se desarrollaron en sus espacios de trabajo: sala de orientación, laboratorio de ciencias y salones de clase. Solo una entrevista, a petición de la maestra, se realizó en la calle. $\mathrm{Al}$ respecto, Taylor y Bogdan (1992) señalan que quienes investigan solo pueden lograr el rapport con las personas si se acomodan a las rutinas y modos de hacer las cosas de estas últimas. En este sentido, a la maestra 
inicialmente se le propuso ingresar a un café, respondió que acababa de tomar uno y solo deseaba fumar un cigarrillo.

Se realizaron encuentros dialógicos con diez personas integrantes del cuerpo docente. Algunas fueron consideradas informantes clave, razón por la que se establecieron, con ellas, conversaciones informales y reiterados encuentros dialógicos en torno a temas cada vez más específicos. Para Woods (1998), quienes son informantes clave abren perspectivas en todo el frente metodológico ya que pueden convertirse en fuentes de grandes volúmenes de información. En efecto, los encuentros reiterados con estas personas permitieron esclarecer las dudas que surgían de lectura de las primeras entrevistas.

Las entrevistas con el estudiantado se desarrollaron con aquel considerado por el personal de orientación como personas potencialmente violentas o victimas y victimarios de bullying (cabe destacar que en esta escuela identificamos dos casos de bullying, pero no los abordamos en este artículo). En ambos casos los diálogos tuvieron como eje articulador los incidentes violentos en los que participaron. Después de escuchar, transcribir y leer repetidas veces las entrevistas, encontramos aspectos que eran nombrados tangencialmente y otros que no lográbamos entender. Para superar esta dificultad elaboramos un listado de esos temas y los abordamos en diálogos más específicos. Y con el propósito de obtener una perspectiva más amplia de esos temas, desarrollamos algunos encuentros grupales con el alumnado. Este participó ávidamente y las conversaciones fluyeron de manera sincera.

Los primeros acercamientos con el estudiantado tuvieron un matiz de desconfianza. En las primeras entrevistas no se expresaban con libertad, se limitaban a decir que les daba pena (en México significa vergüenza). Esta actitud fue cambiando en el transcurso del trabajo de campo. El estudiantado perdió el miedo y se logró establecer un clima agradable. Así, los encuentros de entrevista se convirtieron en espacios para hablar en libertad, incluso para utilizar algunos términos considerados groseros y que se evitan en el diálogo cotidiano con el personal docente.

Cabe señalar que durante el tiempo de trabajo de campo hubo espacios inaccesibles, como el espacio de reuniones en los que se toman decisiones sobre la permanencia o no del alumnado en la escuela. Estas decisiones se hacen a puerta cerrada. Por eso los pormenores no son revelados y solo en algunos casos tuvimos información de terceras personas.

\section{LA VIOLENCIA NO ES UNA, SON MUCHAS}

Es frecuente que quienes narran noticias o el personal docente nombren como bullying a cualquier incidente de violencia en las escuelas. Estas afirmaciones solamente son puntos de vista asociados al sentido común. Pues no todas las acciones que pueden contribuir a crear un clima de inseguridad en la escuela o lesionar la integridad del estudiantado pueden tipificarse como bullying. Sabemos que este concepto denota las conductas de intimidación o acoso intencionadas y sistemáticas por medio de las cuales un sujeto o un grupo de estudiantes atenta contra la integridad física, material o emocional de algunas o algunos compañeros (Olweus, 2006). Este comportamiento inaugura un proceso de victimización en el que el sujeto agresor adquiere la condición de sujeto victimario, por medio de la imposición abusiva del poder y la víctima adquiere esa condición cuando tiene dificultades para defenderse y se encuentra en desventaja ante victimarios.

Lo expresado en el párrafo anterior pone bajo sospecha la costumbre de designar como bullying una diversidad de conductas que van desde los juegos bruscos hasta los ajustes de cuenta. Además, estas conductas son difíciles de delimitar y catalogar como violentas, pues el umbral para designarlas de ese modo es difuso, ya que su reconocimiento depende de marcos significativos diversos. Ciertamente, para calificar un determinado comportamiento como violento se debería tener en cuenta la situación concreta en la que se produce y lo que significa para quienes participan en su producción (Buenfil, 2012). Interesa, entonces, analizar desde la perspectiva del alumnado aquellos hechos interpersonales que exceden la problemática del bullying y que afectan la sana convivencia en la escuela, al crear un clima poco propicio para la relación educativa. En este 
sentido, presentamos agrupados en cuatro subtítulos historias relacionadas con los juegos bruscos, el ajuste de cuentas y la intervención de las familias de estudiantes y otras personas externas en episodios que podrían calificarse como violentos.

\section{Las Pambas: "El que Se lleva, se aguanta"}

En México, la pamba es un juego que se trasmite de generación en generación. Es una actividad lúdica que une a grupos de amistades de barrio, compañeros y compañeras de aula, hermanos hermanas y familiares. En el caso de esta escuela, la pamba es una práctica común y su intencionalidad difiere en los grupos que lo practican. Algunos lo hacen para divertirse y hacer relajo cuando el personal docente no asiste a clase. Otros, para poner a prueba su resistencia al dolor, ya que las reglas del juego implican propinar y recibir golpes rudos. La rudeza de algunas pambas alienta su prohibición y, paradójicamente, estas restricciones incitan el placer de transgresión. Incluso sabiendo que no están permitidas, su práctica es cotidiana. Esto puede deberse a que las percepciones y apreciaciones del personal docente y de quienes practican las pambas son heterogéneas. Veamos como algunas maestras describen las pambas:

Cuando entre comillas estamos jugando-le digo entre comillas porque la mayoría de las veces no se dice oye vamos a jugarhay un tema sobre el cual estamos hablando, una sintonía sobre la cual se están llevando y alguien sale con una bobada, entonces, nos vamos contra él y le damos pamba. Por ejemplo todos estamos diciendo colores: azul, morado y llega otro y dice plato y entonces pamba con ese, por bobo. Se sobreentiende que le queremos castigar porque rompió con la sintonía y pues entonces hay que darle pamba. La otra modalidad de la pamba es que pase por tres. Es decir, él tiene que ir pasando y le damos uno, dos, tres. Todos le pegamos tres veces. En la otra pamba todos corren y hacían bola. Lo nuevo es que pasas por tres, todos tenemos que darle tres golpes... . Los niños son muy listos y saben delante de quién lo hacen. En el salón lo hacen dependiendo de qué maestro esté. Si están solos lo hacen, pero hay maestros permisivos que no quieren meterse en problemas y dejan que los niños hagan lo que quieren. (Olga)

... Muchos pegan a uno, solo en su cabeza. Para unos es un comportamiento normal del grupo, pero yo le digo que no, porque a veces cuando alguien no aguanta la pamba, al rato termina "cantándole el tiro", como ellos dicen, al otro. (Zoila)

Las pambas son el corolario de un desbordamiento de energía que se expresa en golpes. El juego a veces surge súbitamente y el alumnado que participan en él es capaz de interpretar sus prohibiciones y sabe que cuando sobrepasa los límites transgrede el principio que lo regula. Cuando esto sucede se produce un conflicto y se pone en peligro la convivencia. Es decir, la persona que ha sido objeto de un golpe que considera excesivo o que ha rebasado las prohibiciones del juego termina recurriendo a la pelea (cantarle el tiro) para dirimir lo que considera ofensa.

En la escuela, paradójicamente este juego es prohibido, pero también consentido. Algunos miembros del personal docente lo toleran y hasta lo promueven. Tal es el caso que el alumnado se da pamba en los diferentes espacios de la escuela. No les importa la presencia o ausencia del personal docente. Además, son pocos los integrantes del cuerpo docente que interpretan estos episodios como violentos y que reclaman una intervención especializada o que sugieren una sanción ejemplar. Ahora bien, las pambas más rudas y posiblemente más dolorosas son protagonizadas por estudiantes varones y lo hacen en ausencia del personal docente y fuera del espacio escolar, generalmente a la hora de salida.

En todas las formas de pambas existe una cierta complicidad en el sentido de que cada quien sabe hasta dónde llegar. Es decir, conoce el principio del juego: "el que se lleva, se aguanta". Sin embargo, el deseo de revancha de los sujetos que han recibido un golpe demasiado brusco hace que se imaginen una pamba cada vez más cruel. Así, poco a poco estos comportamientos se convierten en conductas violentas que se dirimen en pelas concertadas.

Prosiguiendo con el tema, veamos ahora el punto de vista de estudiantes varones que participan directamente en las pambas bruscas. Para lograr que estos construyan una narrativa sobre el tema, se organizó un grupo focal a partir de una lista de alumnos reportados por su participación en pambas. Más de 
quince alumnos estaban dispuestos a participar. La mayoría de estos fueron del primer grado de educación secundaria. Unos a otros se empujaban por ingresar a la sala de orientación. Ingresaron diez y se sentaron en círculo de acuerdo con las indicaciones. El resto se quedó fuera jugando y empujándose en la puerta. Minutos después la profesora orientadora les ordenó que regresaran a sus aulas.

$\mathrm{Al}$ inicio de la actividad, el grupo reía y celebraba las denominaciones y descripciones de cada pamba. Cada intervención se hacía con mucha picardía, algunas denominaciones de las pambas fueron pronunciadas a susurro. Al transcurrir media hora de ávidas participaciones, sus voces e intenciones fueron cambiando. Se escuchó frases como "tengo pena" (vergüenza) y como ideas fugaces se vislumbró una que otra reflexión. Los siguientes párrafos sintetizan las descripciones que algunos estudiantes hacen de las pambas.

Todo empieza con una cisca. Nos hacemos así (hace un ademán de pegar una cachetada) y si se asusta le llamamos a todos y le pegamos así (hacen el gesto de un golpe en el pecho, en el antebrazo, omóplato, cabeza y orejas). Cuando se golpea en el pecho se dice pechugo. (Estudiante 1, Grupo focal 3. Turno matutino)

Cuando vine a esta escuela vi que las pambas eran de puro zapes, entonces les dije hágale así, así y les enseñé todas las pambas. Y es que haga de cuenta que yo vivo en un barrio y ahí todos son maleantes, ellos lo hacen, lo vi allá y vine a enseñar aquí. ¡Ah! se dice pamba bombón, cuando al que le hacemos la pamba tiene que inflar los cachetes y le damos un puñetazo, también hay el carnero y otros más como el taco. ¡Ah! el de pistolón lo aprendimos en la calle. Como todos nos vamos juntos los vimos como lo hacen los dedos como pistola y les pegan en el cuello. Ajá, los aprendimos y comenzamos a ciscarnos y darnos. (Estudiante 2. Grupo focal 3. Turno matutino)

Según estos relatos, cualquier estudiante que está dispuesto a involucrarse en el juego puede hacerse merecedor de los golpes que dan contenido a la pamba. Este lo acepta sin ofrecer ningún tipo de resistencia, pues conoce el principio implícito que ordena el juego. Así, la pamba es celebrada por los estudiantes con carcajadas.

Habría que decir también, que las pambas de alguna manera están influenciadas por problemas sociales como las pandillas, la delincuencia y la exclusión social. En efecto, el discurso de uno de los estudiantes deja entrever que la experiencia escolar está atravesada por los problemas sociales (violencia, delincuencia, exclusión) que experimenta el estudiantado en los espacios donde fluye la cotidianidad de sus vidas. En este caso, el contexto en el que se desenvuelve la vida cotidiana del estudiante influye en el aprendizaje de cierto tipo de pambas que podrían considerarse como potencialmente violentas. Probablemente el estudiantado aprende en el barrio a dominar ciertas habilidades, valores y actitudes que le ayudan a sobrevivir en esos espacios, pero que no siempre contribuyen a la sana convivencia en la escuela (Ortega y Mora, 2005). Tal es el caso, que el estudiante al parecer no es consciente del daño que las pambas rudas les pueden ocasionar. Además, se siente orgulloso de enseñarlo y practicarlo con sus compañeros de la escuela.

Conviene ahora decir que la imaginación de los estudiantes ha permitido crear o mejorar las características de las pambas. Pero en cualquiera de los casos, la intensidad del golpe es el aspecto distintivo. El nombre de algunas de ellas está asociado con la parte del cuerpo que sufre el golpe. Los siguientes testimonios ilustran esta afirmación.

El ojitos, te estiran los párpados. El chichi negra y chichi blanca, te aprietan las tetillas. Te dicen negra o blanca. Si dices blanca y no le atinas te giran las tetillas al otro lado, entonces tienes que decir negra para que te dejen. Hay otros como el chirihuaso y los cheetos. (Estudiante 2. Grupo focal 3. Turno matutino)

También practicamos el penezaso o guajolotero, se practican en nuestro barrio, es muy conocido, todos te pegan en la cara de un lado hacia otro. (Estudiante 5. Grupo focal 3. Turno matutino).

Yo hago más el jeringazo, me gusta pegar en el nervio de la espalda, el brazo se duerme con cada golpe, es como que te inyectan en la espalda pero con los dedos doblados y con fuerza te cae el puño. (Estudiante 4. Grupo focal 3. Turno matutino)

Un compañero te presiona los testículos y te exige chiflar y no se puede. A veces nos cogen por detrás y no te sueltan los testículos, no puedes ni respirar. Casi a todos nos han hecho esto. A mí me hizo una mujer. Y no sé por qué no se puede chiflar ... (Estudiante 7. Grupo focal 3. Turno matutino)

Yo explico el saca cacas porque yo lo hago. Se hace con el puño, se pega con fuerza en el ano y también se hace con el pie. No lo hago a diario, solo lo hice a dos niños del salón (menciona los nombres de sus compañeros). Mis compañeros estaban inclinados sobre sus carpetas y se me ocurrió hacerlos. Se le puso ese nombre porque a los niños que lo hacemos nos dicen 
que si les duele mucho y se les afloja el estómago, da ganas de hacer, por eso se llama así. A mí también me lo hicieron. Hace poco tiempo trajeron uno peor, se llama saca mierda. En esa pamba te ubican agachado y te pegan con la rodilla en el ano o con la punta del zapato. Se siente la sensación de hacer del baño, duele mucho el estómago, es como estar estreñido. El dolor dura de dos a tres días, no puedes ir al baño, si vas no puedes hacer porque se siente duro, por más que haces así (hace fuerza, empuña sus manos y como pujando gime). Ah, tampoco puedes sentarte y se queda un moretón (todos ríen al escuchar la descripción). (Estudiante 4. Grupo focal 3. Turno matutino)

Como se ve, las pambas son cada vez más rudas. Quienes la practican no dimensionan la gravedad y los efectos que puede tener en la salud física de quien la padece. Al parecer, la crueldad del golpe lejos de constituirse en un factor disuasivo, alimenta el morbo. Tal es el caso que su práctica se ha incrementado, tanto en número de participantes como en el nivel de rudeza, esto considerando la fuerza y la parte del cuerpo elegida para ser golpeada (cara, cabeza, vientre, brazos, tórax, espalda, genitales, ano).

Por otra parte, como señalamos al comienzo, son muy pocos los estudiantes que muestran su desacuerdo con las pambas. Pero esta disconformidad no se manifiesta abiertamente, pues son más los que disfrutan con el dolor ajeno y con el suyo. Otros, cuando se distancian ligeramente de esa práctica para elaborar un discurso sobre esta, experimentan sentimientos de enojo, ganas de venganza, coraje, miedo, dolor. Veamos lo que dicen al respecto.

Yo me siento muy enojado, a veces me pegan muy fuerte y me da mucho coraje, me da ganas de vengarme pero no puedo regresarlo. A veces me duele mucho porque me dan con la punta del zapato. (Estudiante 1. Grupo focal 3. Turno matutino)

Yo no estoy de acuerdo en llevarme así. Me siento mal porque llegan y pa te tiran cuando no te estas llevando y me quedo con el coraje. Un día un señor nos vio y dijo que nos iba a reportar a la patrulla que estaba ahí y justo nos estaba siguiendo la policía y nos tuvimos que correr. (Estudiante 3. Grupo focal 3. Turno matutino)

Yo estoy de acuerdo cuando todos se llevan. A veces te llevas pero estás de malas y no aguantas y el grupo no entiende y entonces pamba contigo, y eso no se vale. Aunque a veces o casi siempre hay algo que te han hecho antes, entonces ves la oportunidad de vengarte. No se puede acusar porque luego ya te chingaste con el grupo, te van a pegar igual o peor. (Estudiante 5. Grupo focal 3. Turno matutino)

Estos testimonios muestran la percepción negativa de algunos estudiantes hacia las pambas. Además, expresan su malestar y desacuerdo con los golpes que les propinan los otros cuando ellos no están participando del juego. Así, no en todas las pambas, sin importar la magnitud y contundencia del golpe, se respeta el derecho de quien ha decidido no participar en el juego. Esto las convierte en un problema con consecuencias negativas para las relaciones interpersonales. Pues en nombre de estas, algunos alumnos ejercen el poder abusivo que daña al otro.

En las pambas que participan sin ningún tipo de coacción quienes deciden llevarse en ella, aparentemente no hay jerarquías constituidas por victimarios que exhiben un comportamiento de agresividad cruel y víctimas que sufren el calvario de la agresión. Empero, se convierte en incidente violento cuando el alumnado es sometido a la pamba sin su consentimiento. Para Saucedo (2006), la regla de llevarse y aguantarse entre estudiantes es un recurso cultural simbólico que usan los grupos de jóvenes para mediar sus acciones en juegos que implican el uso de la fuerza. En estas acciones, señala la autora, ponen a prueba su resistencia mutua a acciones que podrían intimidar o molestar en otras circunstancias.

En resumen, todos los testimonios glosados dibujan las pambas como un juego brusco; es decir, que están cargadas de actos físicos rudos (abofetear, patear, etc.) que dañan o lesionan el cuerpo. Los deseos de desquite hacen que quienes toman la iniciativa en el juego de revancha, perfeccionen la tecnología para lograr que los golpes se tornen más dolorosos y provoquen mayores daños al cuerpo. Esta tendencia, como ya lo han manifestado algunos estudiantes y docentes, convierte el juego en violencia potencial. Genera conflictos interpersonales que amenazan las relaciones de convivencia en la escuela. En más de una vez estos conflictos se han dirimido en pelas a puñetazos y patadas. Así, las pambas terminan generando climas sociales en los que eclosionan lamentables prácticas de abuso, malos tratos y violencia entre iguales. 


\section{Así SE ARMó EL RELAJO: A FRUCTIS, BOING... DE TODO}

Es la hora del receso de la jornada escolar del turno matutino. Desde el pasillo del tercer piso del segundo pabellón se observa el vaivén del estudiantado en el patio. Algunos de ellos forman con sus cuerpos un ruedo. Por sus gestos se deduce que conversan animadamente. De pronto un estudiante aparece por una de las esquinas del patio, camina rápidamente e ingresa al ruedo, agita sus manos y al parecer está hablando con alguien del grupo. Minutos después, los dos estudiantes están en el centro del ruedo y sus compañeros gritan alborotados. Rechiflan y gritan dale, dale. Al compás de estos gritos gran parte del alumnado corre apresurado hasta el patio donde supuestamente se estaba produciendo una pelea. En medio de ese tumulto, avanzan también con prisa la directora y un profesor quienes circunstancialmente estaban platicando en uno de los pasillos del pabellón principal de las aulas.

El profesor se abre camino entre el tumulto y avanza corriendo hacia el patio gritando qué pasa, espérense, no peleen. En medio de la confusión alguien lanza una caja de boing sobre el profesor. Es difícil distinguir quiénes lo lanzan. Se alcanza a ver que son muchos los objetos lanzados en dirección del profesor y la directora. El alumnado corre en todas las direcciones mientras la directora desesperada grita que se active la comisión de guardia. El profesor, sin poder aún salir de su sorpresa, trata de identificar a los infractores y corre hacia el pasillo para protegerse. Se puede ver en el pasillo al personal de prefectura tratando de evitar que el estudiantado escape hacia el patio principal. El alboroto se calma y algunos estudiantes quedan atrapados en el patio. Estos obedecen las órdenes de la directora. Son registrados y reportados.

Vale la pena destacar que este incidente no es un hecho frecuente en la escuela. Al parecer, fue un suceso banal que rápidamente se transformó en un incidente violento. Sospechamos que es el corolario descontrolado de repudio al control ejercido por una parte del profesorado. Los siguientes relatos resultan particularmente ilustrativos sobre el caso que estamos viendo.

En el receso yo estaba en la bolita que estaba empujando, nos aventaron cosas. Corrieron al otro patio, el resto los siguió y yo me quedé. Les aventaron cosas a los maestros, a mí me tocó ver como le aventaban cosas a la directora, le aventaron una paleta ja, ja, ja, ja. Lo buscaban a los maestros y les tiraban. (Estudiante - mujer. Grupo focal 4. Turno matutino)

... todos corrieron al patio de atrás a ver qué pasaba. Yo estaba con él (señala a otro estudiante) y con otros, estábamos platicando y ahí es cuando se armó el relajo. La directora bajó con el maestro (menciona el nombre) y ahí empezaron a fructis, boing, fruta, mango, de todo. Todo iba directo al maestro puesto que le odian, porque es muy estricto, porque cae mal. (Estudiante mujer. G. F- 4. Turno matutino)

Estos relatos describen el inicio de un incidente trivial y muy común entre el alumnado. Esto es, empujarse, formar ruedos y hacer bola en el patio, armar alborotos, correr y empujarse. Pero al parecer, la aparición intempestiva de la directora y uno de los profesores para detener una supuesta pelea hace que este incidente, banal en sus inicios, derive en una escalada inusitada de agresiones. Ahora bien, ¿por qué los ataques estaban dirigidos contra las autoridades del colegio?. Los siguientes relatos son elocuentes al respecto.

Sí, él es muy estricto quiere que todo lo hagamos como él quiere. No estamos de acuerdo con el profesor, porque el que tiene el mando aquí y el control es la directora, ella debe saber y manejar la escuela. Es la que debe ver por nosotros, el maestro está detrás de la directora como viendo sus movimientos y no sabe cómo controlar a los alumnos. (Estudiante mujer. G. F - 4. Turno matutino)

Tal vez el maestro nada más está de barbero con la directora porque sabe que cuando la profesora salga de la escuela quiere entrar como director. (Estudiante mujer. G. F - 4. Turno matutino)

... Y luego cuando se pelean afuera, lo único que hace es salir y jalonear a las personas, a los que están peleando y los mete a la dirección. En la última pelea que hubo, nomás les jaloneó aquí afuera y les entró a la escuela y les dejó que caminen solas, las soltó para que no tuviera conflictos con la directora. (Estudiante mujer. Grupo focal 4. Turno matutino)

Es que él, en vez de decir, como otros maestros que nos dicen: tomen consciencia y hagan esto, el maestro (menciona el nombre) nos está regañando y en vez de decirnos si tu puedes, no es que tú y así nos empieza a gritar. (Estudiante mujer. G.F - 4. Turno matutino) 
Este incidente parece articular ciertas formas de conflictividad general de índole emocional o simbólica y hechos específicos de violencia física (Míguez, 2009). En efecto, los relatos evidencian el desencadenamiento de episodios de violencia física probablemente motivados por el trato autoritario y las valoraciones negativas que uno de los profesores hace del alumnado. El estudiantado cuestiona al profesor su forma de relacionarse, su modo de comunicarse y su autoritarismo. Expresa su queja y, a la vez su reclamo cuando dice que el profesor, lejos de valorar sus aspectos positivos y animarlos, les regaña y les grita. Sin duda, las valoraciones negativas que el profesor hace del alumnado afectan el concepto que construyen de sí mismos. Puede generar que acaben convenciéndose que son incapaces o violentos, no porque realmente lo sean, sino porque el maestro les está transmitiendo ese mensaje. Como contrapartida, existe entre el personal docente quienes contribuyen al establecimiento de buenas relaciones en el espacio escolar. Así lo confirma una estudiante cuando dice que "otros maestros los animan y los invitan a reflexionar sobre sus actos".

En definitiva, el episodio violento que hemos descrito se inscribe en la dinámica de interacción de la escuela. Dicho de otro modo, está vinculado directamente con el clima institucional que se vive en la escuela (Míguez, 2009). Al menos, eso se puede deducir de los relatos glosados y los registros de observación. Habría que decir, también, que la actitud autoritaria del profesor y la desaprobación, por parte del estudiantado, de la autoridad que este reclama para sí, asumiendo un rol que no le corresponde, configura un ambiente de conflictividad en el que la institucionalidad escolar está directamente implicada.

\section{AJuste De Cuentas: Cantando EL tiro}

En esta escuela, además de las pambas y otros episodios de conflictividad general se acostumbra realizar ajuste de cuentas. Esta aparente forma de solucionar los problemas es una práctica común entre el alumnado. También es un recurso que utilizan algunos padres/madres de familia para enfrentar los problemas en los que se ven envueltos sus hijos o hijas. Los ajustes de cuentas se dan dentro y fuera del centro educativo y se inician con conductas de agravio y menosprecio. En suma, una comunicación violenta que termina en el uso de la fuerza física. Veamos lo que dicen algunas estudiantes al respecto.

En mi salón nos llevamos pero jugando. Nos decimos las típicas groserías de: ¡chinga tu madre! pero sabemos que estamos jugando, las mujeres también lo decimos. Aunque ya después alguien no aguanta y dice ya perdóname o nos vamos a los golpes. Hace poco tuve un problema con una niña de segundo. Le dije de cosas. En la salida cuando ya iba para mi casa, todos se echaron a correr y yo fui para el chisme a ver quién se va a pelear, pero luego se paró en frente. Me dijo: ¿qué si nos íbamos a pelear? Yo me empecé a calentar y entonces le dije: ya bájale de huevos, se puso frente de mí, entonces nos pusimos a pelear, mi amiga y sus amigas. Esto ya había empezado aquí dentro. Aquí todo es chisme. Las del problema se van a decir: me voy a pelear y se corre la voz, se van a pelear, se van a pelear. Ya sabemos donde ir. Aunque a veces, como ayer, igual se pelearon aquí afuera en la esquina. (Estudiante 1. Turno matutino Grupo Focal 4)

Una que se peleó es mi compañera. Ella se sienta detrás de mí y le estaba diciendo a otro compañero que estaba emperrada, yo voltee y le pregunté por qué estaba enojada y dijo que una de tercero le había “cantado el tiro”. Me enseñó una conversación en su celular donde ella le pone "pinche güera de rancho" y ella no se dejó y le dijo de cosas. En el recreo se fue con sus amigas a decirle de cosas, pero su hermana se metió y quedaron que en la salida. Ya hasta estaban listas con el chongo, y en la salida se agarraron de las greñas. Para pelear se preparan, se hacen su chongo. Yo me quedé a mirar y vi que todos se iban y que voy al chisme y en eso sacan todos sus celulares, para grabar y subir al Facebook. Ya se empezó a ver que se estaban agarrando, luego salió el maestro H. Estaban todos subidos en las banquetas. No más vi cuando el maestro las estaba separando, ni podía separarlos. La de tercero estaba toda arañada de la cara y la cara bien roja. (Estudiante 2. Turno matutino. Grupo focal 4)

La primera vez me peleé con una chica de mi salón porque le metieron cizaña. Le dijeron que yo había dicho que era una bulímica y en la salida me reclamó. Yo le dije: tengo suficientes huevos y si tengo que decirte algo, voy y te digo en tu jeta. Pues va cámara, "un tiro" me dijo. Luego nos empezamos a pelear al otro lado en la esquina del metro bus. Me empujó, le empujé. Nos dijimos de cosas y peleamos. Lo grabaron, un chavo me envió a mi Facebook. (Estudiante 2. Turno vespertino. Grupo focal 2)

Los discursos revelan que los conflictos entre el alumnado se dirimen de la manera menos racional: cantando el tiro. Cuando esto sucede, los compañeros o compañeras de las contrincantes, si es que no se lían 
a golpes, graban y miran la pelea alentando a sus compañeras. Ahora bien, ¿̨por qué se suscitan los problemas que terminan en enfrentamientos cuerpo a cuerpo?, ¿qué es lo que caracteriza estos episodios de violencia? Los discursos antes señalados dibujan ciertas líneas que nos permiten insinuar dos respuestas posibles: las relaciones entre el estudiantado están marcadas por el despliegue de conductas de agravio y menosprecio, y las peleas se instituyen como una forma de visibilización y expresión de valentía.

Las conductas de agravio y menosprecio tornan violentas las relaciones entre el alumnado. En efecto, el lenguaje grosero entre quienes no se llevan es entendido como un atentado contra la dignidad. La ofensa inmediatamente es dirimida cantando el tiro; es decir, se traduce en acciones de violencia física.

También las riñas entre compañeras están motivadas por el interés de salir de la invisibilidad dando muestras de valentía. En el marco escolar, el interés de las estudiantes por lograr una posición respetable, no solo en el círculo de amistades, sino también en el grupo clase y el centro escolar, opera a través de provocaciones (lenguaje soez y rumores) y respuestas que se materializan en luchas cuerpo a cuerpo. En este proceso, juega también un papel importante el grupo de referencia de estudiantes que se lían a golpes. Al parecer, las expectativas implícitas o explicitas del grupo hacen que las estudiantes asuman el riesgo de enfrentamientos cuerpo a cuerpo. En efecto, los pares de grupo siempre están incitando las peleas. Cuando estas se producen, siempre las graban, las suben al Facebook y las miran con entusiasmo. Situadas en el lugar que están buscando, las estudiantes se enorgullecen de su presencia en la red y comentan con orgullo la pelea. Celebran y agradecen a quienes difunden sus peleas.

También la determinación para enfrentar a quien agrede y resolver el conflicto a golpes supone tener huevos y quienes los tienen son populares entre las amistades por su fuerza y valentía. Las chicas pueden ser muy femeninas; pero con los huevos bien puestos para enfrentar los agravios, no solo con palabras, sino también, con la fuerza física. Al respecto, Barraza (2015) señala que las nuevas generaciones forman parte de un momento cultural en el que el léxico, antes exclusivo de los varones, hoy también es de las mujeres. Sin embargo, el uso de este lenguaje como el tener huevos, chinga tu madre, etc. es censurado por los sujetos adultos. Mas no es así entre estudiantes, ya que su uso es común y su connotación depende del momento, del tono de voz y de a quién va dirigido.

A continuación, veamos cómo los estudiantes varones dirimen con las estudiantes mujeres las acciones de agravio y menosprecio. En términos generales, los varones utilizan dos estrategias. La primera supone actuar del mismo modo que sus ofensoras, es decir, agraviarlas y menospreciarlas. Si el conflicto no queda zanjado recurren a la ayuda de una compañera dispuesta a liarse a golpes. Un estudiante lo cuenta del siguiente modo.

Todo empieza por los chismes, te dicen que eres joto o puto, uno se enciende va y reclama. Ayer, según una chava le robaron el cuaderno y llega a insultar: "pinches rateros" y uno se saca de onda. Uno sabe que la pedrada es para uno. Le dije: india, mejor cállate india, te robaron india tu champú para que te bañes y empezó a decirme que tiene mucha lana. Me saqué de onda y había una que es media gordita, le dije cállate pinche obesa. Saben que yo robé (ríe) en la mañana, por eso estoy en la tarde .... Dan ganas de pegarles, pero te das cuenta que no son hombres. A las mujeres solo los ofendemos verbalmente, nos llevamos de palabra, les decimos algo que les cala y ya no se aguantan y les hiere. Por ejemplo: pinche fea, apestosa, caes mal, pero sí que caen mal, hasta la madre... . Por pegarle a una chamaca te pueden demandar y vas para el tutelar. Pero hay otra manera de arreglar ese asunto. Mandándole a alguien para que le pegue porque una mujer con una mujer si se puede. A veces hacemos el trato, le decimos a una amiga que trance, que una se está pasando de lanza y párale en seco y va le reclama, le dice: no te estés metiendo con este chavo. Ayer ya envié una chava y hoy le iban a parar de cabeza por mí porque la chava estaba de faltosa. (Entrevista a estudiante 1 de tercer grado. Turno vespertino)

En este caso, al igual que los anteriores, el agravio y el menosprecio fractura las relaciones interpersonales. Los agravios se resumen en sentencias como joto, puto, pinches rateros y el menosprecio en palabras como pinche fea, apestosa, india. Con este lenguaje se hace saber a la otra persona que es menos y que no merece ningún aprecio. Aquí vale la pena hacer una digresión para aludir a la connotación que adquiere la palabra india en la escuela. En este espacio, lo indio se asocia con elementos culturales y raciales supuestamente inferiores. Aunque el discurso formal ha cambiado, el racismo está profundamente arraigado en el imaginario 
del estudiantado. Estos sentimientos y creencias negativas se expresan en calificativos que tienen clara intención de hacer que los otros seres se sientan rechazados y avergonzados de sí mismos (Rodríguez, 2010).

Los roces que estos incidentes generan, a diferencia de lo que sucede entre mujeres, no se resuelve inmediatamente recurriendo a la violencia física. Quienes se sienten ofendidos, responden agraviando y menospreciando a la ofensora. Pero no participan directamente en las peleas cuerpo a cuerpo por temor a ser denunciados y encarcelados. Si la tensión continúa incitan la intervención de una tercera persona, en este caso, una mujer. De este modo las relaciones interpersonales se recrudecen y finalmente la intolerancia estalla en luchas violentas cuerpo a cuerpo.

En los discursos glosados, podemos leer también que las peleas son concertadas en los diferentes espacios de la escuela. Pero la lucha no se desencadena en este espacio, quizá porque saben que serán contenidas en el intento y porque serían objeto de sanción inmediata. Ahora bien, el grupo de estudiantes que forman parte del círculo de amigas y amigos de las contrincantes, participan incitando y publicitando las peleas. En algunos casos los enfrentamientos se producen en un lugar que todos conocen, incluso el personal docente (dos parques cercanos a la escuela). En otros casos, la tensión es tanta que la lucha se produce en la acera contigua a los muros de la escuela. Cuando esto sucede algunos miembros del profesorado intervienen para contenerlos. Tal es el caso, que uno de ellos, al primer aviso, salía de la escuela y se abría espacio entre el grupo de observadores para detener las peleas. Sin embargo, después de un incidente, el papá de una de las estudiantes liadas acusó al profesor de agresión física contra su hija. Frente a estas acusaciones, decidió no volver a intervenir. Además, no consiguió que sus acciones fueran respaldadas por las autoridades educativas.

En suma, los problemas escolares, sociales y psicológicos se entrecruzan en el devenir de la convivencia en la escuela. Tales problemas convergen en un entorno escolar caracterizado por una frágil integración del estudiantado. Este ambiente facilita la construcción de gestos de agravio y menosprecio que se dirimen en enfrentamientos cuerpo a cuerpo. De este modo, las estudiantes demuestran su valentía y buscan el reconocimiento del grupo de pares. Aquí se ve bastante bien la pluralidad de significaciones que puede tener la violencia (Dubet, 1998). Esta tiene más de un sentido para el estudiantado. Como hemos visto, le permite resolver un conflicto, defenderse a sí mismo y al otro ser, hacer catarsis y reivindicarse socialmente cuando se siente menospreciado.

\section{VENIMOS A PARTIRLE LA MADRE}

Son las dos y diez minutos de una tarde fría de otoño, el alumnado del turno vespertino ingresa parsimonioso a sus salones. Tres mujeres adultas que lograron ingresar junto al estudiantado se sientan junto mí en la banca ubicada en el pasillo contigua al patio. Una de ellas le susurra a la otra: en cuanto sube, yo voy tras de la chava y tú entretienes al prefecto. Órale, responde. Y tú (refiriéndose a la tercera mujer) me ayudas por si otras chavas la defienden. La profesora Teresa baja por los escalones, me saluda e inmediatamente pregunta a las mujeres: ¿y ustedes qué hacen? En ese instante, una de ellas exclama ¡ahí viene! y automáticamente avanza en dirección de la estudiante, esta reconoce a la mujer e instintivamente corre y se para junta al prefecto. A ver qué les pasa, para qué han venido, pregunta la maestra Teresa. Es que esa chava le ha dicho cosas a mi hija y venimos a partirle la madre. Órale pues, y ahora van a tomar la justicia por sus manos igual que las mismas chavas, replica enérgicamente la maestra. Seguidamente les conmina a salir de la escuela. Las mujeres obedecen y salen cadenciosas mirando de reojo a la estudiante. El prefecto se mantiene callado. Cuando las mujeres se pierden por el portón, la estudiante camina cabizbaja a su aula. Mientras esto sucede la maestra dice ¡habrase visto! qué ejemplo quieren dar esas mujeres a sus hijos. Ya están tomando por costumbre venir ajustar cuentas aquí.

El acto intimidatorio que pudo haber tenido efectos muy nocivos y perversos se puede leer desde tres vértices. El primero alude a sentimientos de frustración, resentimiento e insensibilidad por la condición humana. El segundo se refiere al deterioro de la credibilidad de la escuela para afrontar con éxito el 
recrudecimiento de las relaciones interpersonales en la escuela. El tercero, insinúa un abierto desafío y desprecio por la institucionalidad.

Este hecho demuestra que no todas estas conductas violentas son producidas en la escuela. Se imbrican con otros factores sociales y culturales que le dan poder y significado. No hay duda de que el amago intimidatorio contra la estudiante protagonizado por tres personas adultas es la expresión del quiebre de las relaciones sociales entre iguales, posiblemente no atendidas adecuadamente en el ámbito escolar. Pero, también, deja entrever el debilitamiento de la autoridad institucional. Pues las personas adultas invaden el espacio escolar para intentar dirimir los conflictos en los que se involucran sus hijos e hijas. Este hecho revela un claro desprecio por la autoridad instituida formalmente en la escuela.

Un mensaje importante que se deriva de este incidente es la necesidad de acortar las distancias culturales y asegurar la coherencia entre la formación que propone la escuela y el que está implícito en el ámbito de la convivencia familiar y del barrio en el que se encuentra inserta la escuela. Esto es particularmente importante, ya que son los individuos quienes a través de su participación colaboran en la construcción de los contextos y los vinculan al transitar de uno a otro (Saucedo, 2012). En este sentido, es el estudiantado y otros actores educativos quienes vinculan el espacio social donde viven con la escuela.

En este mismo orden de ideas, el siguiente relato permite entender cómo los significados de la vida social que se producen, circulan y consumen (García, 2004) en los diversos espacios sociales penetran en el mundo escolar.

... esa vez me vinieron a pegar aquí por un mal entendido, me confundieron con un chamaco. Yo me hice de palabras con un
señor y cuando yo estaba peleando con uno, el otro me descontó pegándome en la mandíbula ... Es que sabe, soy bueno para
los golpes, pero sí, lo acabé. Le gané a los golpes y cuando ya la gané se metió el otro señor a pegarme y me peleé con el otro.
Entonces cuando ya no podía más y le iba llevando ventaja, el otro me descontó y me golpeó la nariz, ahorita me lo arreglaron
por eso .... Había mucha gente. Ese día lo llamé a mi papá pidiéndole apoyo, la familia de mi papá vino y les andaba buscando
a los señores, les dio miedo y se dieron cuenta con quien se habían metido. Una vez los correteamos y vinieron a hablar con
el director. Es que mi papá anda en diferentes lados. Trabaja no en cosas buenas, pero trabaja. Tiene varios puntos donde
vende droga, bueno, él no lo vende, otros, le pagan por desaparecer gente. Me llevo a todo dar. Se ve bien tranquilo, bien
chaparrito, pero, se pasa de lanza. Por eso que no vivo con él porque a mi mamá no le gustó esa vida, como a ella le daba miedo
que termine en la cárcel y aparte que es bien mujeriego, la engañó. A pesar de lo que es, no me dice: va y rájale por gente que
no la debe, pero a gente que la debe rómpele la madre ... esa vez me suspendieron seis días, pero me han suspendido como
cuatro veces, pero el coraje sigue. (Entrevista a estudiante 1 de tercer grado. Turno vespertino)

Este discurso evidencia que los incidentes violentos en los que se implican estudiantes y en los que participan otras personas, podrían considerarse como manifestaciones de la violencia social. El hecho de que ocurran muy cerca de los muros de la escuela y al final del tiempo escolar, no los convierte en problemas vinculados directamente con la dinámica escolar. Sin embargo, comportan conductas y riesgos reales para la convivencia en el espacio escolar, pues lo invade y lo desestabiliza, porque le pone problemas no escolares, problemas psicológicos y sociales que la escuela no puede tratar (Dubet, 1998).

Tal es el caso que el estudiante en sucesivas conversaciones admite con presteza que participa en actividades y comportamientos usualmente prohibidos en la escuela, como liarse a golpes con sus compañeros y robar. Pero también comparte ese tipo de comportamientos con otros grupos estigmatizados en su barrio. Y es por conflictos gestados en ese contexto que se produce el incidente glosado. Por ese tipo de conductas ha sido separado reiteradamente de la escuela. Sin embargo, esas sanciones no lo disuaden o no lo convencen para que cambie su manera de actuar. Por el contrario, el estudiante percibe que las sanciones son venganzas.

Este caso es un claro ejemplo de la importancia que tiene la familia y el espacio social más próximo en el proceso de socialización de la juventud. En estos espacios construyen significados, entre otros aspectos, sobre las relaciones sociales. Si allí aprenden que los conflictos se resuelven recurriendo a la violencia, probablemente con esos mismos esquemas de pensamiento y acción resolverán las situaciones conflictivas que se presentan en la vida. No obstante, ni la familia, ni la escuela suelen dar la debida importancia a esas 
cuestiones. La reacción se desencadena cuando el estudiantado manifiesta conductas indebidas e incluso ilícitas.

Con lo dicho hasta aquí hemos intentado caracterizar, a partir de los registros de observación y los discursos de los actores educativos, diversas formas de violencia como, los juegos bruscos, formas de conflictividad general y el ajuste de cuentas. Asimismo, visibilizamos algunos mecanismos que subyacen a los hechos de violencia, analizando el entramado de relaciones y significados que supone la confluencia de la diversidad en la cotidianidad de la vida en la escuela.

\section{ANÁLISIS DE RESULTADOS: VIOLENCIAS SISTÉMICAS Y VIOLENCIAS RELACIONALES}

Los testimonios glosados en los apartados precedentes muestran que algunas acciones conflictivas entre el estudiantado y de este con el personal docente eclosionan en situaciones de violencia. Estas se manifiestan en formas disímiles de agresión física (peleas, ataques a docentes) y verbal (calificativos denigrantes entre compañeros y compañeras), daño emocional (actitudes de menosprecio, expulsiones del aula de clase, vulneración de las formas convencionales de interacción en el aula) y hostigamiento. Es más, las acciones entre el alumnado se inician como juegos (pambas) y derivan en situaciones de tensión y violencia física. Retomando los aportes de Míguez (2007), nombramos a estas acciones como violentas, no solo por la producción del daño físico, sino también, porque algunos actores educativos lo viven como la imposición de una fuerza arbitraria externa que los afecta. Aunque algunas de esas acciones, como las expulsiones del aula de clase, parecen estar naturalizadas.

Tomando como referencia las contribuciones teóricas de Míguez (2007), las violencias aludidas en el párrafo precedente, se podrían agrupar en violencias sistémicas y violencias relacionales. Habría que agregar también las formas de violencia que provienen del contexto sociocultural.

Las formas de violencia relacionadas con la función de la escuela están asociadas a la función que debe cumplir la escuela y al mantenimiento de un orden asimétrico. A manera de ejemplo, glosamos el ataque a la directora y a un profesor con residuos de comida. Vale la pena destacar que esta acción, al parecer un suceso banal, transformado rápidamente en un problema de violencia, es el corolario descontrolado del repudio a la normalización autoritaria del comportamiento del estudiantado. Es preciso anotar que este tipo de incidente no caracteriza a la totalidad de las relaciones en la escuela. Pero podría ser el corolario de formas imprecisas de relaciones asimétricas que tienen el propósito de configurar las subjetividades del estudiantado. Según los relatos y los registros de observación, estas serían relaciones que pretenden normalizar el comportamiento del alumnado y, paradójicamente, relaciones basadas en el consentimiento de comportamientos, en potencia, perjudiciales.

En efecto, hemos podido observar que más de un miembro del profesorado ha sido desbordado por el alumnado. Viven y sufren cotidianamente el drama de no poder mantener el orden necesario para el desarrollo de la clase. En contraposición, otros grupos del personal docente intentan frenar los incidentes disruptivos dando órdenes a gritos. Amenazan al estudiantado con reportarlo y expulsarlo del aula. Los incidentes continúan y pronto más de un estudiante sale expulsado del aula y sigue fomentando el desorden en los pasillos. Estas formas de actuar están naturalizadas en la escuela, se las considera como necesarias para la buena formación del estudiantado y estos así lo reconocen. El cuadro se matiza con malos tratos de parte del profesorado, pero también el alumnado agrede a ciertos profesores o profesoras con bolas de papel. Estas relaciones refractarias (Míguez, 2009) producen situaciones de violencia simbólica y emocional, pues tanto el profesorado como el estudiantado se ven envueltos en situaciones a las cuales no les encuentran propósito alguno.

Es prudente advertir que las situaciones de violencia descritas en el párrafo precedente se enlazan con el clima de trabajo escolar que impera en la escuela. Este se caracteriza por la falta de claridad en los roles. Con esto no queremos decir que la vida en las escuelas sería más ordenada si existiese claridad en los roles. Es 
más, pareciera que el estudiantado y el profesorado actúan movidos por una serie de habituaciones, y en situaciones coyunturales lo hacen estratégicamente. En efecto, en esta escuela las relaciones entre el alumnado y el profesorado dependen casi exclusivamente de sus características individuales como de su capacidad para atraer a las otras personas, persuadirlas y así construir buenas relaciones.

Ahora veamos las violencias relacionales o aquellas que ocurren en la interacción entre el estudiantado. Estas se inscriben en procesos heterogéneos e involucran daños físicos, agresiones verbales y actitudes de menosprecio. En este artículo describimos casos de peleas cuerpo a cuerpo entre mujeres y juegos bruscos.

Las peleas entre alumnas que hemos documentado casi siempre son el corolario de conductas de agravio verbal y menosprecio. Lo que significa que los episodios de violencia física se relacionan con situaciones de violencia verbal y emocional. Al parecer, en las peleas que se producen entre mujeres, subyace el deseo de mostrar valentía y ser reconocidas en sus grupos de referencia. En su lenguaje, defender el honor a golpes significa tener los huevos bien puestos. Aquí se nota claramente el predominio de una manera de pensar que sostiene que el hombre es superior a la mujer; pero también, el reclamo de reconocimiento de unas capacidades y unos derechos que tradicionalmente han estado reservados para los hombres.

Estas conductas se despliegan en un entorno escolar en el que las prácticas cotidianas tienden a la homogeneización, la normalización y la rigidez. Esta tendencia homogenizante favorece prácticas en las que el otro diferente es amenaza y es excluido porque no encaja dentro de los parámetros de una supuesta normalidad (Salmerón, 2012). Este ambiente facilita la construcción de gestos de agravio y menosprecio que se dirimen en actos de enfrentamiento cuerpo a cuerpo. Estas peleas no carecen de sentido para el alumnado. Lo entienden como un medio permitido para defender al otro y sí mismo, como una forma de catarsis y como un medio para reivindicarse socialmente ante el menosprecio.

Aludimos ahora a los juegos bruscos, específicamente a las pambas, para precisar que estas prácticas suponen desbordamiento de energía expresada en golpes. Quien se la lleva se aguanta es el principio implícito que rige el juego. Este, a veces surge súbitamente y quienes participan en él son capaces de interpretar sus prohibiciones y saben que cuando sobrepasan los límites trasgreden el principio que lo regula. No obstante, quienes han recibido un golpe demasiado brusco, animados por el deseo de venganza, imaginan pambas cada vez más crueles. Esta tendencia convierte al juego en violencia potencial. Así, poco a poco estos comportamientos, que podrían calificarse como desviaciones toleradas (Dubet, 1998), se convierten en conductas violentas que se dirimen en pelas concertadas.

Ahora bien, no siempre se respeta el derecho de quienes no participan en las pambas. Esto convierte el juego en un problema con consecuencias negativas para las relaciones interpersonales. Pues en nombre de estas, algunos alumnos o alumnas ejercen una fuerza que daña y no es aceptada por el otro sujeto. Esta situación termina generando climas sociales en los que eclosionan lamentables prácticas de abuso, malos tratos y violencia entre iguales.

En cuanto a las formas de violencia que provienen del contexto sociocultural, retomando a Dubet (1998), consideramos que estas son tramas de acción que desafían la institucionalidad. En efecto, las diversas formas de violencia que hemos documento, de alguna manera están influenciadas por problemas sociales como las pandillas, la delincuencia y la exclusión social. Dicho de otro modo, la experiencia escolar está atravesada por los problemas sociales (violencia, delincuencia, exclusión) que experimenta el estudiantado en los espacios donde fluye la cotidianidad de sus vidas. Probablemente estos aprenden en el barrio a dominar ciertas habilidades, valores y actitudes que les ayudan a sobrevivir en esos espacios, pero que no siempre contribuyen a la sana convivencia en la escuela.

Asimismo, en esta escuela hemos observado también que personas extrañas invaden el espacio escolar para ejercer violencia física contra dos estudiantes y una profesora. Este último caso ha sido documentado en la investigación, pero no se aborda en este artículo. Estos incidentes, al parecer, se imbrican con otros factores sociales y culturales que le dan poder y significado. En efecto, el amago intimidatorio contra una estudiante y la agresión física contra un estudiante protagonizado por personas adultas son la expresión del quiebre de 
las relaciones sociales entre iguales, posiblemente no atendidas adecuadamente en el ámbito escolar. Pero, también, sugieren el deterioro de la credibilidad institucional. Estos mecanismos de resistencia y desafío a la escuela, desde la perspectiva de Dubet (1998), podrían calificarse como violencias anti-escuela. Mirándolo así, estos incidentes podrían estar expresando el deterioro de los mecanismos para afrontar el recrudecimiento de las relaciones interpersonales en la escuela.

\section{Conclusiones}

Hemos intentado a lo largo del recorrido de este artículo mostrar algunas formas de violencia que se desarrollan en una escuela secundaria de la Ciudad de México. En términos generales, hemos documentado acciones que el estudiantado y el profesorado echan a andar en la escuela y que derivan en múltiples formas de violencia física y verbal, daño emocional y hostigamiento. Nombramos estos hechos como violentos porque el estudiantado y el profesorado los viven como la imposición de una fuerza arbitraria externa que los afecta y, por la producción del daño físico que les produce.

Tomando como referencia estas evidencias y los presupuestos teóricos desarrollados por Míguez (2007, 2009), sostenemos que esas formas disímiles de violencia se pueden agrupar en violencias sistémicas, violencias relacionales y aquellas que provienen del contexto sociocultural. Las primeras están asociadas con la función que debe cumplir la escuela y al mantenimiento de un orden asimétrico. Las segundas son horizontales y ocurren en la interacción entre el estudiantado y de este con el profesorado. Las terceras podrían entenderse como tramas de acción que desafían la institucionalidad. Si bien estas múltiples formas de violencia tienen como escenario la escuela, su gestación rebasa sus límites. Además, muchas de ellas están naturalizadas, como las expulsiones de clase, por ejemplo.

\section{REFERENCIAS}

Barraza, G. (6 abril, 2015,). Diccionario de léxico tabú en el español de México. Boletín UNAM-DGCS-195 Recuperado de http://www.dgcs.unam.mx/boletin/bdboletin/2015_195.html

Buenfil, R. N. (2012). La violencia escolar: Múltiples implicaciones y múltiples ángulos de interpretación. En A. Furlan (Coord.), Reflexiones sobre la violencia en las escuelas (pp. 315-348). México: Siglo XXI.

Dubet, F. (1998). Las figuras de la violencia en la escuela. Pedagogía, 123, 35-45.

García, N. (2004). Diferentes, desiguales y desconectados. España: Gedisa.

Geertz, C. (2003). La interpretación de las culturas. España: Gedisa.

Goetz, J. y LeCompte, M. (1998). Etnografía y diseño cualitativo en investigación educativa. España: Morata.

Gómez, A. y Zurita, Ú. (2013). El estudio de la violencia escolar, orígenes y tendencias. En A. Furlán Malamud y T. Spitzer Schwartz (Coords.), Convivencia, disciplina y violencia en las escuelas (pp. 183-222). México: ANUIESCOMIE.

Míguez, D. (2007). Reflexiones sobre la violencia en el medio escolar. Espacios en blanco. Revista de Educación, 17, 9-35. Recuperado de http://www.redalyc.org/pdf/3845/384539799001.pdf

Míguez, D. (2009). Las formas de violencia en las comunidades escolares. En G. Noel (Coord.), Violencia en las escuelas desde una perspectiva cualitativa (pp 21-35). Argentina: Ministerio de Educación de la Nación.

Míguez, D. (2012). Cavilaciones epistemológicas sobre el estudio de la violencia en las escuelas. Elías y el equilibrio entre el nominalismo y positivismo. En A. Furlán (Coord.), Reflexiones sobre la violencia en las escuelas (pp. 72-101). México: Siglo XXI.

Monoclús Estella, A. (2005). La violencia escolar: Perspectivas desde las Naciones Unidas. Revista Iberoamericana de Educación, 38, 13-32. Recuperado de www.redalyc.org/pdf/800/80003803.pdf

Olweus, D. (2006). Conductas de acoso y amenaza entre escolares. España: Morata. 
Ortega, R. y Mora, J. A. (2005). Conflictividad y violencia en la escuela. Sevilla, España: Diada Editora.

Rodríguez, A. J. (2010). Algo más que el orgullo en juego: Discriminación y racismo. En R. Ortega Ruiz, R. Del Rey Alamillo, P. Rojas Pedregosa, y A. G. Unigraf (Eds.), Ser adolescente: Riesgos y oportunidades (pp. 55-64). Córdoba, España: Autor-editor.

Salmerón, A. M. (2012). Notas para una reflexión en torno a la violencia horizontal en las escuelas entre el conservadurismo y la intolerancia. En A. Furlan (Coord.), Reflexiones sobre la violencia en las escuelas (pp. 375-397). México: Siglo XXI.

Sautu, R. (2005). Todo es teoría. Objetivos y métodos de investigación. Argentina: Lumiere.

Saucedo, C. (2006). Estudiantes de secundaria. Sus apropiaciones de recursos culturales para recrear su condición como jóvenes en la escuela. Revista Mexicana de Investigación Educativa, 11(29), 403-429. Recuperado de http:// www.redalyc.org/articulo.oa?id=14002905

Saucedo, C. (2012). La indisciplina y la violencia en las escuelas, una visión desde la psicología cultural. En A. Furlan, Reflexiones sobre la violencia en las escuelas (pp. 236-253). México: Siglo XXI.

Taylor, S. J. y Bodgan, R. (1992). Introducción a los métodos cualitativos de investigación. Barcelona, España: Paidos. Woods, P. (1998). La escuela por dentro. Barcelona, España: Paidós Ibérica.

\section{BY-NC-ND}

